\title{
Evaluation of Histopathologic Changes in Pulp and Follicle Tissues in Impacted Third Molar in Patients Under 40 Years of Age
}

\author{
Khadijeh Abdal ${ }^{1}$, Sara Haidari², Mohammad Reza Hafezi Ahmadi ${ }^{3}$, Marzieh Darvishi ${ }^{4}$ Faezeh Abdalbeygi $^{5}$
}

${ }^{1}$ Department of Oral and Maxillofacial Pathology, Faculty of Dentistry, Ilam University of Medical Sciences, Ilam, Iran. 2Department of Oral and Maxillofacial Radiology, Faculty of Dentistry, Ilam University of Medical Sciences, Ilam, Iran.

${ }^{3}$ Department of Pathology, Ilam University of Medical Sciences, Ilam, Iran. ${ }^{4}$ Department of Anatomy, Faculty of Medicine, Ilam University of Medical Sciences, Ilam, Iran. ${ }^{5}$ Postgraduate Student, Dentistry Faculty, Ilam University of Medical Sciences, Ilam, Iran.

\section{ABSTRACT}

\section{BACKGROUND}

Removal of third molars is one of the most commonly used procedures in dental surgery. Awareness of the pattern of impaction and associated pathologies can prevent a number of specific problems. The purpose of this study was to evaluate the incidence of third molar tooth and its histopathology in patients referred to the dental clinic of Ilam University of Medical Sciences.

\section{METHODS}

This descriptive-analytic study was conducted on patients who for any reason complained of impacted third molar teeth. In this evaluation, 50 impacted teeth with normal follicular space were measured in panoramic radiography. Then, under local anaesthesia, follicle and tooth were removed by surgery and placed in a $10 \%$ formalin container. The specimens were stained with $\mathrm{H} \& \mathrm{E}$ after preparation in the lab. Then, the histological profile of the tooth and its pulp structure were studied. The hard tissue of the teeth was placed in a $5 \%$ nitric acid solution before cutting. Data obtained from this study were analysed using descriptive statistics (mean, standard deviation, percentage and frequency) and Fisher's exact test (chi-square) and software SPSS Ver.19. Significance is reported at $\mathrm{p}<0.05$.

\section{RESULTS}

Out of 50 dental follicles examined, $44 \%$ (22 cases) of pathologic changes showed that $20 \%$ had inflammation. Of these, 16 cases (32\%) were related to male patients and 34 cases $(68 \%)$ were related to female patients. The percentage of pathologic changes in the follicles obtained from female patients was $77.3 \%$ (17 cases) and in male patients $(22.7 \%)(n=5)(p=0.17)$. The age range was $19-40$ years. The mean and standard deviation of the age of the patients was $26.7 \pm 1.5$, most of them in the third decade of age. There was no statistically significant relationship between age and pathologic changes ( $\mathrm{p}=0.17)$. Of the examined cases, 32 follicles $(64 \%)$ were related to the maxilla and 18 of the follicles (36\%) were related to the jaw. Pathologic changes in maxilla were $18.1 \%$ ( 4 cases) and in lower mandible (81.9\%) (18 cases). There was no significant correlation between the location of follicles in third molar teeth and pathologic changes $(\mathrm{p}=0.37)$. Comparing frequency of dental pulp cells include odontoblast, fibroblast and immune cells, there was no statistically significant difference, $(p=0.610)$.

\section{CONCLUSIONS}

Pathologic changes related to aging in dental pulp and follicle of impacted wisdom tooth is inappreciable; remaining impacted wisdom tooth doesn't lead to clinical/pathologic problems in patients, but it is recommended to extract these teeth in young ages (below 35) so as to accelerate healing process and reduce surgery complications.

\section{KEY WORD}

Tooth Follicle, Pulp, Pathologic Changes

\author{
Corresponding Author: \\ Marzieh Darvishi, \\ Department of Anatomy, \\ Faculty of Medicine, \\ Ilam University of Medical Sciences, \\ Ilam, Iran. \\ E-mail:darvish-m@medilam.ac.ir
}

DOI: $10.14260 / j e m d s / 2019 / 671$

Financial or Other Competing Interests: None.

How to Cite This Article:

Abdal K, Haidari S, Ahmadi MRH, et al. Evaluation of histopathologic changes in pulp and follicle tissues in impacted third molar in patients under 40 years of age. J. Evolution Med. Dent. Sci. 2019;8(41):30893093, DOI: 10.14260/jemds/2019/671

Submission 13-07-2019,

Peer Review 25-09-2019,

Acceptance 01-10-2019,

Published 14-10-2019. 


\section{BACKGROUND}

An impacted tooth is a kind of embedded tooth that is prevented from eruption due to a physical barrier within the path of eruption or is impacted in the jaw due to failure to erupt.(1) In some findings, the rate of impaction of the third molar approaches $85 \%$.(2) One of the most common etiological factors in tooth impaction can be insufficient space due to stenosis of the dental arc and tooth bud angulation.(3) Impacted third molars, which may be asymptomatic and evidenced only in radiography, can have pathological lesions such as cysts or tumours in the follicle sometimes causing pain, tooth displacement, bone expansion, or even bone erosion.(4,5)

Although impacted third molars are often removed for therapeutic purposes, there is still no general agreement on the need to remove asymptomatic third molars.(6-7) Cabber et al., in their study, suggested extraction of impacted third molars for preventive purposes in order to reduce the complexity and difficulty of a subsequent surgical procedure $(8,9)$. Rakprasitkul advocated that impacted third molars should be extracted before they undergo pathological changes. He suggested that impacted third molars in patients over the age of 20 should be extracted even in the absence of pathologic lesions; however, Tulloch concluded that surgery may not be cost-effective for all impacted third molars aimed at preventive purposes. ${ }^{(10,11)}$ Although the National Public Health Institutes advocates the extraction of third molars, many scholars are asking if it is necessary to extract third molars based on a typical process. ${ }^{(12,13)}$ It was suggested in one study (Citation) that extraction of third molars was based on radiolucency changes in the impacted tooth radiography; however, in some other studies, it was emphasized that histopathological changes in impacted third molars are not necessarily related to radiological changes of the impacted tooth. $(7,10,14)$ According to some studies, the radiolucent area surrounding the crown of the tooth should be at least 3-4 mm in diameter in the dentigerous cyst (Follicular cysts). However, radiographic findings of dentigerous cysts do not have a diagnostic value, since many other odontogenic and nonendogenic tumours may have radiographic characteristics similar to dentigerous cysts.(1)

In a study by Adelsperger, who examined 100 impacted third molars without evidence of abnormal pericronal radiolucency, it was concluded that radiography is not a reliable indicator for the accuracy of indicating dental follicular disease.(15) In Saravana, Baykul, Rakprasitkul, and Mesgarzadeh' studies on cystic changes in the dental follicle associated with radiographically normal impacted mandibular third molars, the incidence of cystic changes on impacted third molars' follicles were $46 \%, 59 \%$ and 53\%, respectively. These studies also suggested that histologic and radiographic evaluation of impacted third molars should be used and the third molar should be extracted from the mandibular before pathological changes in pericoronal tissue. $(16,17)$ Considering the results of these studies and the high incidence of cystic changes in the third molar follicle with age regarding normal radiography, the present study was conducted to examine the histopathologic evaluation of follicle and pulp of untrusted third molars.

\section{METHODS}

The sample size of this descriptive cross-sectional study was estimated to be 50 considering Seyyed Majidi et al. In this study, individuals between the ages of 19 to 40 in two groups of men and women were referred to the dental school due to impacted third molar extraction and were examined. All ethical issues related to working with human samples were considered during this study and consent form were obtained from patients after explaining the method of work.

\section{Inclusion Criteria}

Patients under 40 years of age, no pain, inflammatory or clinical symptoms, no systemic or syndromic disease, and normal radiographic view of the third molar.

\section{Exclusion Criteria}

Pregnant women, teeth with lesions (Cysts and Tumours), and patients with specific or systemic diseases. Data obtained from this study were analysed using descriptive statistics (Mean and standard deviation, percentage and frequency) and Fisher's exact test (Chi-Square) and software SPSS Ver.19. Significance is reported at $\mathrm{p}<0.05$.

\section{Methodology}

This cross-sectional study was performed on teeth obtained from surgery of impacted third molars in patients referred to the surgery department at Ilam Dental School during 2018. Initial information was recorded for each patient for desired tooth about the panoramic radiography and tooth impaction type. Then the follicular crest was measured up from maximal distal and mesial prominence of the third molars and from follicular crest to the tip of third molars' cusps using a digital caliper. Each measurement was repeated twice, and the maximum follicular width of each tooth was recorded. Cases where the impacted follicular space was not measurable were excluded from the study. Then patients underwent surgery. Surgery was performed under local anaesthesia. Impacted third molars with the follicle were extracted and put in a $10 \%$ formalin solution immediately for fixation. Tooth hard tissue was placed in $5 \%$ nitric acid solution for 3 days before cutting. Finally, a histopathologic examination was conducted under a tissue passage after preparing 5-micron sections of paraffin blocks, the microscope slides were stained with haematoxylineosin (H \& E). Lams prepared by an oral maxillofacial pathologist who is aware of clinical and radiographic characteristics of lesions were examined by light microscopy. To evaluate the number of cells in the pulp tissue, a magnified $8 \mathrm{x}$ magnification lens with a magnification of 40 was used and reported according to the following formula: number of cells= cell number per millimeter square $\times 40 \times 8$.

\section{RESULTS}

Of 50 follicles in third molar teeth, 16 cases (32\%) were male patients and 34 cases (68\%) were female. Microscopic evaluations showed that $44 \%(n=22)$ of dental follicles had pathological changes, $20 \%$ of which were the inflamed type. The percentage of pathological changes in the follicles obtained from female patients was $77 \%(n=17)$ and $23 \%$ 
$(n=5)$ in male patients. The mean and standard deviation of patient age was $26.7 \pm 1.5$; most patients were in their third decade of age (Table 1).

\begin{tabular}{|c|c|c|c|c|c|c|c|}
\hline \multirow[b]{2}{*}{ 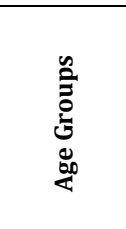 } & \multicolumn{6}{|c|}{ Medical Diagnosis } & \multirow[b]{2}{*}{$\mathbf{p}$} \\
\hline & 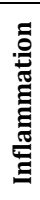 & 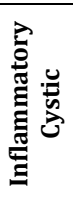 & 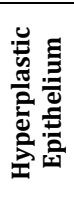 & 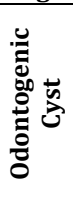 & 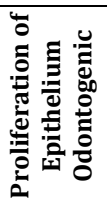 & 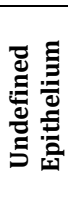 & \\
\hline 11-29 Years & 9 & 1 & 2 & 3 & 3 & 20 & \multirow{2}{*}{0.89} \\
\hline $30-40$ Years & 1 & 1 & 0 & 1 & 1 & 8 & \\
\hline
\end{tabular}

Based on Fisher's exact test (chi-square), no significant relationship was found between age and pathological changes $(p=0.890)$. Of the examined cases, $32(64 \%)$ follicles were related to the maxilla and $18(36 \%)$ to the mandibular. Pathological changes in the maxilla were $18 \%(n=4)$ and $82 \%$ $(n=18)$ in the mandibular. Based on a chi-square test, there was no significant relationship between the impaction type of unerupted third molars and pathological changes $(p=0.370)$.

No significant difference was found between the frequency of dental pulp cells, including odontoblasts, fibroblasts and immune cells ( $\mathrm{p}=0.610$; Figures 1 and 2). A comparison between the frequency of collagen fibers and vascular sections was determined by increasing age in the pulp, but this difference was not statistically significant $(\mathrm{p}=0.502$; Figures 3 .

\begin{tabular}{|c|c|c|c|c|c|}
\hline \multicolumn{2}{|c|}{$\begin{array}{l}\text { Histological } \\
\text { Assessment }\end{array}$} & Female & Male & $\begin{array}{l}19-29 \\
\text { Years }\end{array}$ & $\begin{array}{l}29-30 \\
\text { Years }\end{array}$ \\
\hline \multirow{3}{*}{ Fibroblasts } & Low density & $15 \%$ & $10 \%$ & $20 \%$ & $18 \%$ \\
\hline & $\begin{array}{c}\text { Medium } \\
\text { density }\end{array}$ & $35 \%$ & $30 \%$ & $30 \%$ & $32 \%$ \\
\hline & \begin{tabular}{|l} 
High density \\
\end{tabular} & $50 \%$ & $60 \%$ & $50 \%$ & $50 \%$ \\
\hline \multirow{3}{*}{ odontoblast } & Low density & $18 \%$ & $25 \%$ & $25 \%$ & $15 \%$ \\
\hline & $\begin{array}{c}\text { Medium } \\
\text { density }\end{array}$ & $38 \%$ & $30 \%$ & $30 \%$ & $25 \%$ \\
\hline & High density & $44 \%$ & $50 \%$ & $45 \%$ & $60 \%$ \\
\hline \multirow{2}{*}{$\begin{array}{c}\text { Vessels and } \\
\text { nerves }\end{array}$} & Low density & $20 \%$ & $20 \%$ & $40 \%$ & $30 \%$ \\
\hline & \begin{tabular}{|l} 
High density \\
\end{tabular} & $80 \%$ & $80 \%$ & $60 \%$ & $70 \%$ \\
\hline \multirow[t]{2}{*}{ collagen } & Low density & $40 \%$ & $35 \%$ & $30 \%$ & $40 \%$ \\
\hline & \begin{tabular}{|l|} 
High density \\
\end{tabular} & $60 \%$ & $55 \%$ & $70 \%$ & $60 \%$ \\
\hline \multirow{3}{*}{ Immune cell } & Low density & $10 \%$ & $8 \%$ & $20 \%$ & $10 \%$ \\
\hline & $\begin{array}{c}\text { Medium } \\
\text { density }\end{array}$ & $30 \%$ & $35 \%$ & $30 \%$ & $40 \%$ \\
\hline & High density & $60 \%$ & $47 \%$ & $50 \%$ & $50 \%$ \\
\hline \multicolumn{6}{|c|}{$\begin{array}{l}\text { Table 2. Relative Frequency of Cellular Pulp Tissue } \\
\text { Characteristics of Erupted Third Molars }\end{array}$} \\
\hline
\end{tabular}

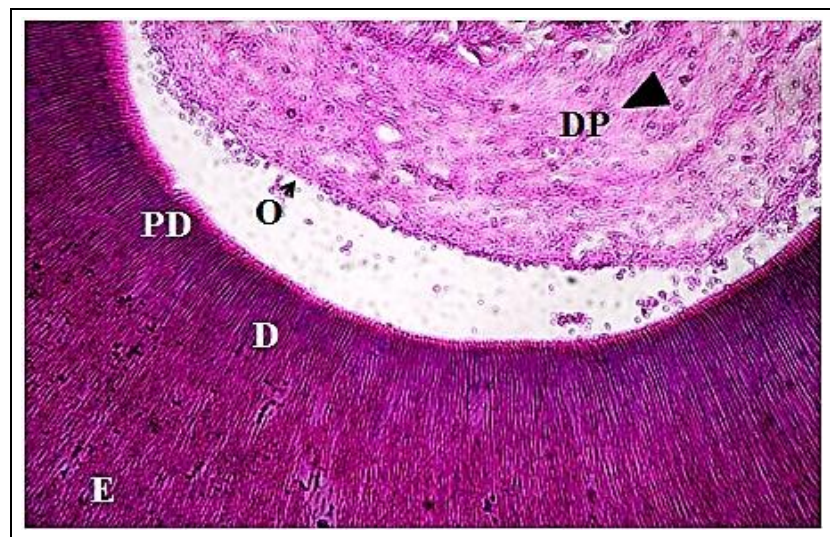

Figure 1. The Structure of the Tooth Pulp that Contains the Odontoblastic Layer Adjacent to the Pre-Dentin Area. H \& E Staining with 40x Magnification). DP: Dental Papilla, PD: Pre-Dentin, $O$ : Odontoblast, D: Dentin, E: Enamel

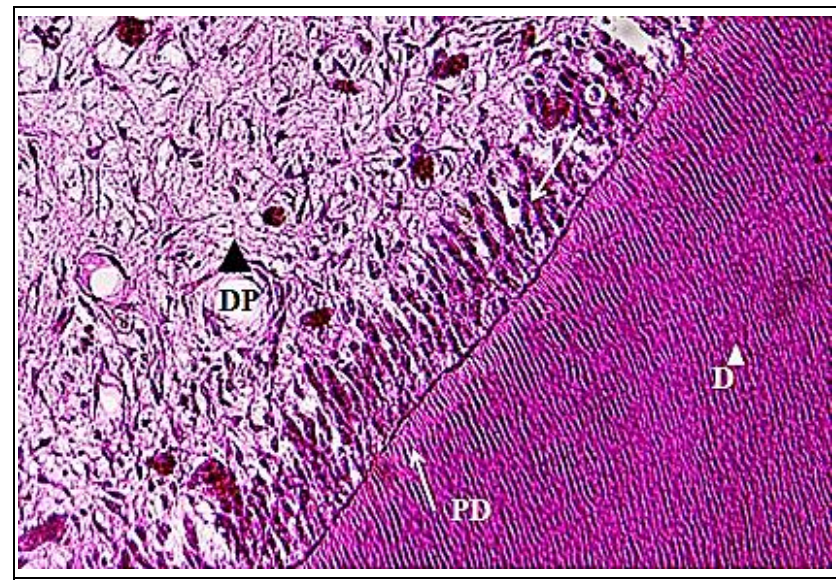

Figure 2. The Structure of the Tooth Pulp that Includes Fibroblast, Odontoblastic Layer and Collagen Fibres in the Pulp Matrix $(H \& E$ Staining with 40x Magnification. DP: Dental Papilla, PD: Pre-Dentin O: Odontoblast, D: Dentin

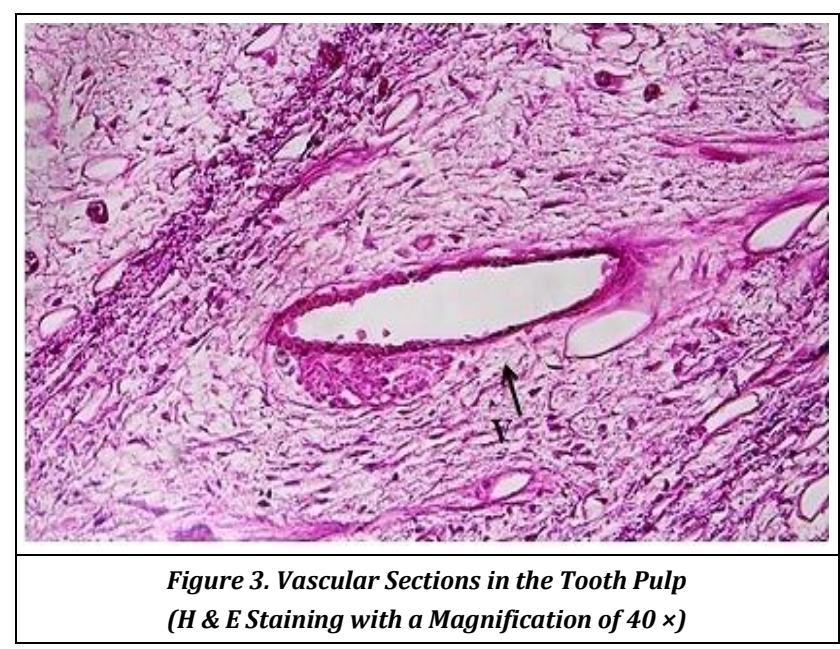

\section{DISCUSSION}

Across all humans, regardless of race, third molars are the last teeth that grow and erupt. The average age when third molars erupt is 20 years old. The delay in the eruption affects the impaction of a large number of third molars, up to $98 \%$ of all impactions for third molars. The assessment of the condition and progression of dental bud growth for better control of the patient seems necessary to reduce impaction rate as well as problems associated with impacted teeth such as per coronate, periodontal disease, decay, erosion of adjacent tooth root, and cyst and tumour formation. ${ }^{(18)}$ In this study, based on the fact that the growth of the third molar is usually complete at the age of 17 , and by the age of 20 third molar scan be identified with inadequate space or inadequate position with greater confidence than at the age of 17 , the age group of 20 to 40 years was chosen.(19) Dentists are often confused in deciding whether or not to extract asymptomatic third molars. Different findings are on a spectrum from "long-term follow-up by observation of a problem to preventive extraction in young ages."(20) In this study, we examined the incidence of impaction types in third molars and their pathologies to determine whether or not the pathology of the impacted tooth was so advanced that preventive removal of the asymptomatic tooth should be performed. Considering that $68 \%$ of unerupted third 
molars follicles are related to women, the almost two-fold incidence in women could be significant.

These results may in part be because women's physical growth usually stops at puberty, after which third molars begin growing, but men continue to grow throughout their teenage years until the third molar eruption around the age of $20 .(19,20)$ Hashemipour et al. found that there was a significant difference between sex and impaction(6) in the evaluation of the impacted teeth of 1,020 patients in south-eastern Iran. Kwaketal. also studied 1,000 Chinese patients in Singapore and showed a significant relationship with impacted teeth in women.(21) In a radiographic study of the symptomatic impacted mandibular third molars in southern Africa, Qirreish found that women were twice as prone to develop symptomatic impactions.(22) The statistical insignificance in the present study could be a result of a small sample size compared to the above-mentioned studies, although several studies have also shown no correlation between impacted third molars and patient. In Hassan' study, there was no significant difference between men in Saudi patients (Citation).

Sigaroodyetal in their study on impact on patterns in the Iranian population, found that there was no significant difference between the frequency of impacted third molars in men and women.(23) In the present study, most patients were in their third decade of life; that is, the majority of patients were under the age of 40 , which could indicate an increased awareness of the community about oral health.(24) Hashemipour et al. found most people were in the third decade of life. (61) As a result of his study, Maita said that $63 \%$ of the subjects were in the age group of 20-30 years.(25) According to a study by Chuet al. on impacted teeth of 7,486 people in Hong Kong, more than half of the participants were in the third decade of life.(24) Considering that in this study, $64 \%$ of impacted third molars were related to maxilla, however, pathological changes were seen more frequently (82\%) at the mandibular third molar, which is inconsistent with the results of existing studies. Some studies have reported a significantly higher incidence of impactions in the mandible, $(18,21)$ while other studies reported that the incidence of maxillary was almost twice as high as mandibular. $(26,27)$ One of the main goals of this study was to find out the incidence of various pathologies in impacted third molars. We obtained the prevalence of sex, age, and involved jaw, which we will further compare to the results of other studies. Of the 50 dental follicles examined, $44 \%$ showed pathologic changes, $77 \%$ of which were related to impacted third molars in women. In a study by Guven et al., of 235 patients with lesion-impacted third molars, $42 \%$ were female and $58 \%$ were male. Only cysts were examined in Guven's study and the incidence of cysts in males was more prevalent,(28) whereas in the present study, histopathological changes were generally examined. In a study carried out by Seyyed Majidi et al. to evaluate histopathological changes of follicles around 200 third molars, there was no significant difference in normal follicle cystic changes between men and women.(28) In this study, pulmonary tissue cells of impacted third molars were evaluated and showed no significant differences in age or sex variables. In this study, odontoblast cells adjacent to predentin, fibroblast cells in all areas of the pulp and immune cells, including macrophages and mast cells, were distributed throughout the central areas of pulp. The matrix of the pulp field included collagen strands and substances that were similar to periodontium tissue. The fibroblasts were the most studied cell population, which is consistent with the results of valid references. Generally, the number of pulp cells decreases as age increases, and the ability to repair and palpation cells differentiation decreases, but in this study, there was no significant difference between the number of cells in the pulp in terms of age. Blood vessel sections enter the tooth canal through the apical foramen pulp and are responsible for feeding and blood supply to the tooth pulp scattered across all areas of the pulp. The results of the research show that the number of vascular sections and the ability of pulp tissue regeneration decreases with increasing age, but there was no significant difference between the impacted teeth pulp in patients aged 20-40 years in this study. Considering the fact that no valid study has been done regarding the number of pulp cells in different ages and both sexes, and most studies have been conducted to compare the pulpal cells of human and animal teeth milk and permanent teeth, the results of this study were compared with valid references.

\section{Limitations}

The small sample size and the lack of studies on the evaluation of pulp tissue cells were limitations of this study.

\section{CONCLUSIONS}

Pathological changes are imperceptible with increasing age in the follicle and pulp of impacted third molars. The presence of impacted third molars does not cause any serious pathological/clinical problem. However, since pulling these teeth is possible with a surgical method, it is recommended that these teeth be removed from the jaws at a younger age (less than 35 years) in order to make the recovery process faster and reduce the complications of surgery. As the tooth follicle disappears with increasing age, and the sample group of patients was less than 40 years of age, in order to examine the microscopic changes in the follicle along with tooth pulp, further studies be performed in a wider age group in order to examine changes in dental pulp and tissue around impacted third molars to study the pathological changes. Considering that there was no significant difference between pulp cell types in both sexes and with increasing age, it is recommended that flow cytometry and electronic microscopy be used in future studies for pulp cell evaluation.

\section{ACKNOWLEDGEMENT}

We would like to thank of Ilam of University of Medical Sciences for their support for this research. This article is the result of a research project at the Ilam University of Medical Sciences that has an ethical code number IR.MEDILAM.REC.1397.086, and all rights reserved to the Ilam University of Medical Sciences. 


\section{REFERENCES}

[1] Neville BW, Damm D, Allen CM, et al. Oral and maxillofacial pathology. $3^{\text {rd }}$ edn. St. Louis: W.B. Saunders Co, 2009: p. 590-643.

[2] Ahlqwist M, Gröndahl HG. Prevalence of impacted teeth and associated pathology in middle-aged and older Swedish women. Community Dent Oral Epidemiol 1991;19(2):116-9.

[3] Miloro M, Ghali GE, Larsen PE, et al. A textbook of Oral and Maxillofacial Surgery. $5^{\text {th }}$ edn. Hamilton: B.C. Decker Inc., 2008: p. 194-6.

[4] Saghafi SH, Haraji A, Md. Abadi R, et al. Evaluation of histopathologic changes in impacted third molar follicles in Mashhad dental school in 2005. J Mash Dent Sch 2007;31(3):171-6. (Persian).

[5] Craig RM, Wescott WB, Correll RW. A well-defined coronal radiolucent area involving an impacted third molar. J Am Dent Assoc 1984;109(4):612-3.

[6] Adelsperger J, Campbell JH, Coates DB, et al. Early soft tissue pathosis associated with impacted third molars without pericoronal radiolucency. Oral Surg Oral Med Oral Pathol Oral Radiol Endod 2000;89(4):402-6.

[7] Glosser JW, Campbell JH. Pathologic change in soft tissues associated with radiographically 'normal' third molar impactions. Br J Oral Maxillofac Surg 1999;37(4):259-60.

[8] Guven 0, Keskin A, Akal UK. The incidence of cysts and tumors around impacted third molars. Int J Oral Maxillofac Surg 2000;29(2):131-5.

[9] Cabbar F, Guler N, Comunoglu N, et al. Determination of potential cellular proliferation in the odontogenic epithelia of the dental follicle of the asymptomatic impacted third molars. J Oral Maxillofac Surg 2008;66(10):2004-11.

[10] Rakprasitkul S. Pathologic changes in the pericoronal tissues of unerupted third molars. Quintessence Int 2001;32(8): 633-8.

[11] Tulloch JF, Antczak-Bouckoms AA, Ung N. Evaluation of the costs and relative effectiveness of alternative strategies for the removal of mandibular third molars. Int J Technol Assess Health Care 1990;6(4):505-15.

[12] Stanley HR, Alattar M, Collett WK, et al. Pathological sequelae of "neglected" impacted third molars. J Oral Pathol 1988;17(3):113-7.

[13] Stephens RG, Kogon SL, Reid JA. The unerupted or impacted third molar-a critical appraisal of its pathologic potential. J Can Dent Assoc 1989;55(3):201-7.
[14] Friedman JW. The case for preservation of third molars. CDA J 1977;5(2):50-6.

[15] Brooks SL, Woolfolk C. Prognosis of third molar impactions, a longitudinal study. J of Dent Research 1996;75:333.

[16] Dachi SF, Howell FV. A survey of 3,874 routine full-mouth radiographs. I. A study of retained roots and teeth. Oral Surg Oral Med Oral Pathol 1961;14(8):916-24.

[17] Moreira DE, Del Valle RM, Alonso RLR. Correlation between radiographic image and histological aspects of the pericoronal sack of retained third molars. Rev Cubana Estomatol 1977;14(3):137-44.

[18] Sandhu S, Kaur T. Radiographic study of the positional changes and eruption of impacted third molars in young adults of an Asian Indian population. J Oral Maxillofac Surg 2008;66(8):1617-24.

[19] Fielding AF, Douglass AF, Whitley RD. Reasons for early removal of impacted third molars. Clin Prev Dent 1981;3(6):19-23.

[20] Venta I, Turtola L, Ylipaavalniemi P. Change in clinical status of third molars in adults during 12 years of observation. J Oral Maxillofac Surg 1999;57(4):386-9.

[21] Lomholt JF, Russell BG, Stoltze K, et al. Third molar agenesis in Down syndrome. Acta Odontol Scand 2002;60(3):151-4.

[22] Qirreish EEYJ. Radiographic profile of symptomatic impacted mandibular third molars in the Western Cape, South Africa. [Thesis]. Western Cape: Univ Western Cape, Sep 2005.

[23] Mead SV. Incidence of Impacted teeth. Int J Orthod 1930;16(8):885-90.

[24] Al-Khateeb TH, Bataineh AB. Pathology associated with impacted mandibular third molars in a group of Jordanians. J Oral Maxillofac Surg 2006;64(11):1598-602.

[25] Ma'aita JK. Impacted third molars and associated pathology in Jordanian patients. Saudi Dent Journal 2000;12(1):16-9.

[26] Hassan AH. Pattern of third molar impaction in a Saudi population. Clinical, Cosmetic and Investigational Dentistry 2010;2:109-13.

[27] Quek SL, Tay CK, Tay KH, et al. Pattern of third molar impaction in a Singapore Chinese population: a retrospective radiographic survey. Int J Oral Maxillofac Surg 2003;32(5):548-52.

[28] Seyedmajidi M, Haghanifar S, Foroughi R, et al. Histopathologic evaluation of normal radiolucent space around impacted third molar. J Mash Dent Sch 2011;35(2):99-106. 